Rajarshi Sannigrahi, MBBS 1

Debangshu Ghosh, MBBS, MS (ENT)

Jayanta Saha, MBBS, MS (ENT)2

Sumit Kumar Basu, MBBS, MS(ENT) ${ }^{1}$

'Department of Ear, Nose, Throat

R.G. Kar Medical College

Kolkata, West Bengal, India

${ }^{2}$ Department of Ear, Nose, Throat

Burdwan Medical College

Burdwan, West Bengal, India
Correspondence: Dr. Debangshu Ghosh

Kalyan Nagar (Near K.G. School)

P.O.-Kalyan Nagar, Via-Panshila

Dist.-24 Parganas (North)

Kolkata-700112, West Bengal, India

Phone: +919038336301 / +919433038925

Email: ghoshdr.d777@ymail.com

The authors declared that this represents original material that is not being considered for publication or has not yet been published or accepted for publication elsewhere, in full or in part, in print or electronic media; that the manuscript has been read and approved by all the authors, that the requirements for authorship have been met by each author, and that each author believes that the manuscript represents honest work.

The authors signed disclosures that there are no financial or other (including personal) relationships, intellectual passion, political or religious beliefs, and institutional affiliations that might lead to conflict of interest.

\section{Traumatic Perforation of the Tympanic Membrane: Etiologies and Risk Factors for Healing and Intervention}

\begin{abstract}
Objective: To study various etiologies of traumatic tympanic membrane perforation; evaluate the factors involved in healing of traumatic tympanic membrane perforation; and identify patients with perforations unlikely to benefit from conservative management.

\section{Methods:}

Design: Prospective observational study

Setting: $\quad$ Tertiary Government Medical College and Hospital

Participants: 64 consecutive cases of traumatic tympanic membrane perforation seen over one year were followed for 3 months. Perforations were assessed in terms of size, etiology, condition of edge and other associated factors or combinations of factors with regards to spontaneous healing using descriptive statistics and chi-square tests.
\end{abstract}

Results: Of the 64 cases, 51 perforations healed while 13 did not. There were significant associations between tympanic membrane condition after 3 months and explosive mode of injury $(x 2=23.30 ; p=.00001)$ as well as with size of perforation $((x 2=25.75 ; p=.00001)$. The risk of persistence of a tympanic membrane perforation was 34.57 times more among patients with a perforation size $>50 \%$ compared to those with perforation size $\leq 50 \%$ [OR-34.57 (6.28, 190.14); $p=.00001]$. Combined, explosive etiology and perforation size $>50 \%$ were significantly associated with non-healing ( $(x 2=37.60 ; p=.00001)$. There were no significant associations with the condition of the edge of the perforation and upper respiratory tract infection.

Conclusions: An explosive etiology and tympanic membrane perforation size $>50 \%$ may be significant risk factors predicting non-healing of the perforation. Risk stratification of patients having one or both of these risk factors with early intervention for those with both, and close monitoring for those with any one of these may lessen unnecessary morbidity. Bigger multicenter future studies are necessary to confirm these initial findings.

Keywords: tympanic membrane perforation, tympanic membrane, risk factors, wound healing, early intervention

Traumatic perforation of the tympanic membrane is a commonly-encountered problem Philipp J Otolaryngol Head Neck Surg 2017; 32 (1): 17-22 (C) Philippine Society of Otolaryngology - Head and Neck Surgery, Inc. 
in our day-to-day Ear, Nose and Throat (ENT) practice. Traumatic perforation can result from blunt or penetrating injuries. Blasts, slaps, rapid airplane descent or deep-water diving can create a column of compressed air within the external auditory canal that can implode the tympanic membrane. Penetrating injuries are mostly self-inflicted but may also be due to procedures like removal of wax or foreign bodies.

In most studies, spontaneous healing of the tympanic membrane happens in about $80 \%$ of cases within 3 months of injury. ${ }^{1}$ Thus, masterly inactivity is the standard mode of treatment for the first 3 months. But in doing so, patients are unnecessarily exposed to disabling symptoms (decreased hearing, discharge from ears) and the need to modify lifestyles for those 3 months. If we can identify the causes of failure of spontaneous tympanic membrane healing after traumatic perforation, we may be able to recommend early intervention and reduce morbidity.

This paper aims to study various etiologies of traumatic tympanic membrane perforation; evaluate the factors involved in healing of traumatic tympanic membrane perforation; and identify the patients who are unlikely to benefit from conservative management so that early surgical intervention may be recommended.

\section{METHODS}

With institutional review board approval, this prospective observational study was conducted in the department of ENT of our tertiary medical teaching institution in Kolkata from January to December 2015. The inclusion criterion was a traumatic perforation of the tympanic membrane irrespective of time of presentation. Patients with history of previous ear discharge or impaired hearing, ear surgery or chronic otitis media in the same ear and patients who were lost to follow up were excluded. A total of 64 patients were enrolled in the study.

After obtaining a history in terms of perforation etiology and duration from occurrence to patient presentation, all patients underwent ENT and general examinations. These included otoscopy, serial tuning fork tests $(256,512$ and $1024 \mathrm{~Hz}$ ) followed by pure tone audiometry (PTA) and impedance audiometry and examination under microscope (EUM) in the operating theatre. The size, site and margin of the perforation were documented by taking photographs. (Figure 1) All the patients were advised to keep their ear dry and follow up regularly every two weeks. All the patients were followed up serially up to three months.

The perforation sizes were compared with the tympanic membrane using ImageJ v.1.47 (open source software, public domain). Statistical analysis included descriptive statistics and chi-square test using Epi Info $^{\text {TM }}$ 3.5.3 (Centers for Diseases Control and Prevention, CDC, Atlanta, GA, USA).
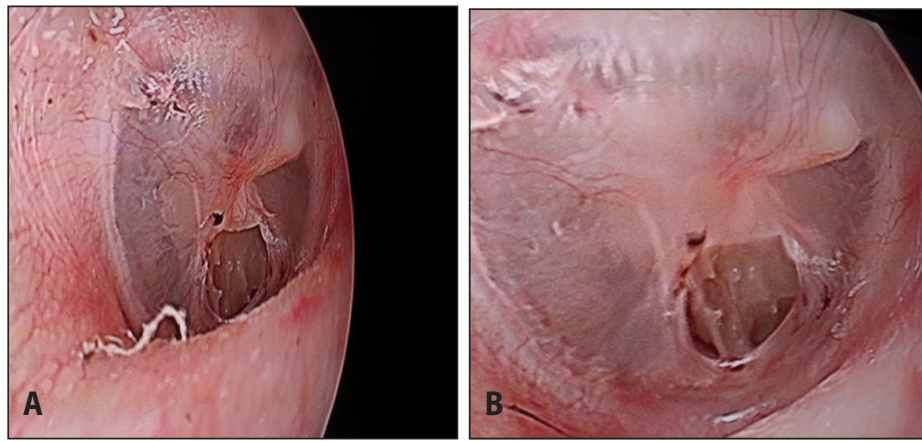

Figure 1. Representative photographs. A. At presentation, showing a $<50 \%$ dry, antero-inferior central perforation and $\mathbf{B}$. Unhealed after 3 months follow up.

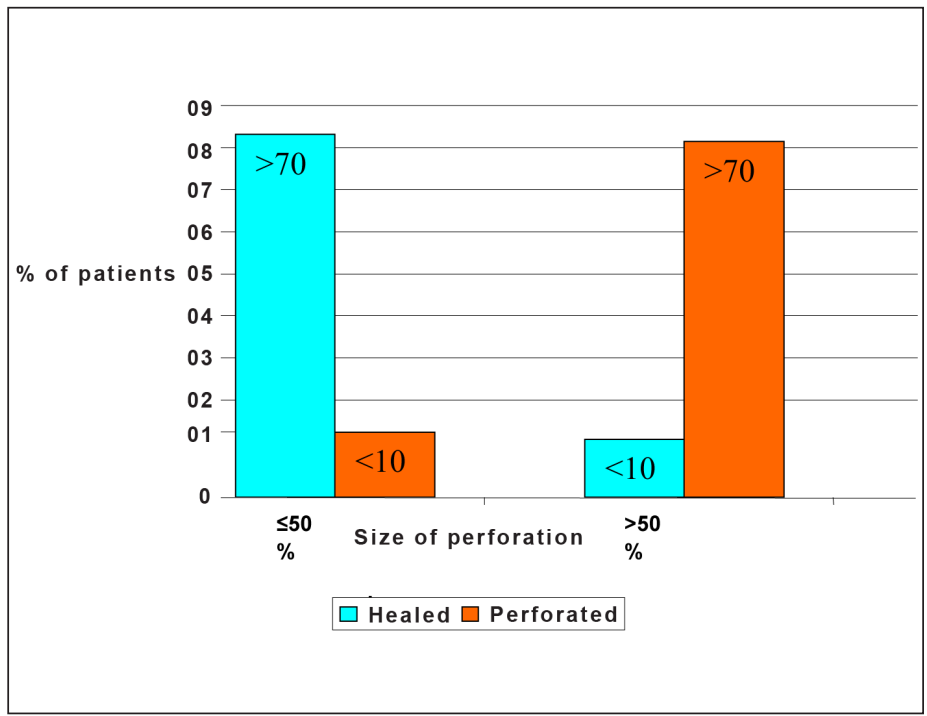

Figure 2. Percentage of patients with perforation size (as percentage $\leq 50 \%$ or $>50 \%$ of total TM surface area) versus healing of tympanic membrane.

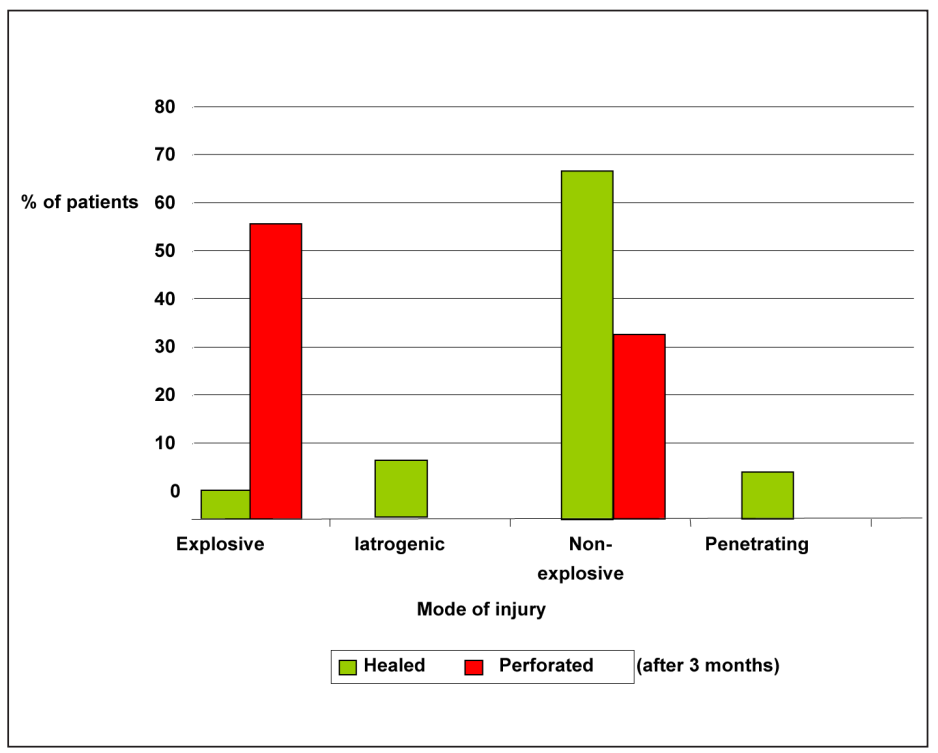

Figure 3. Percentages of patients and etiologies of perforation(explosive or non-explosive) versus condition of tympanic membrane(healed or perforated) after three months. 


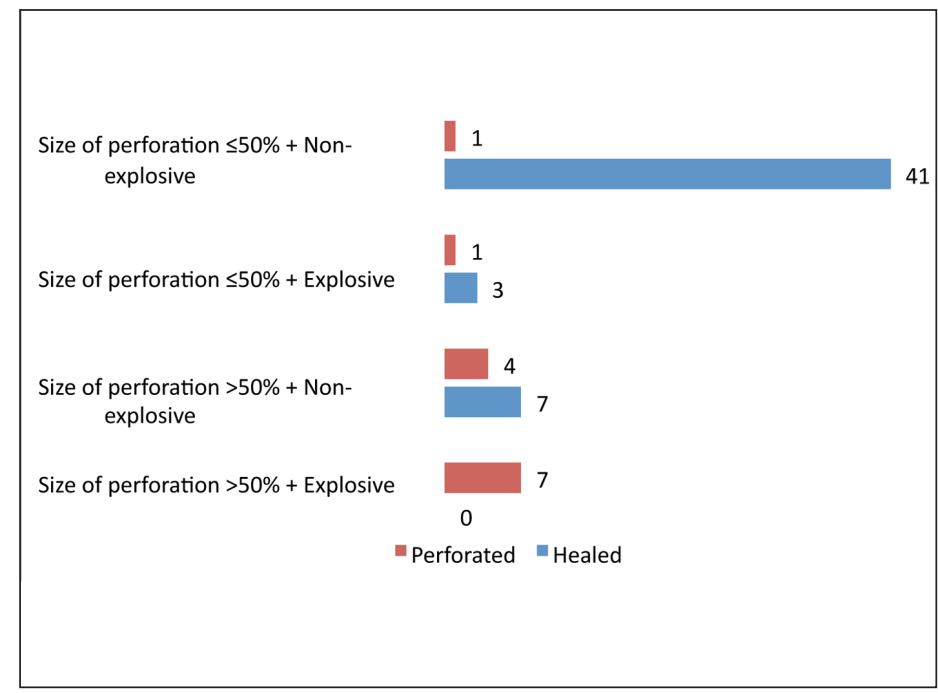

Figure 4. Bar graph showing distribution of persistently perforated and healed perforations based on combined factors (size of perforation $\leq 50 \%$ or $>50 \%$ and explosive and non-explosive etiology).
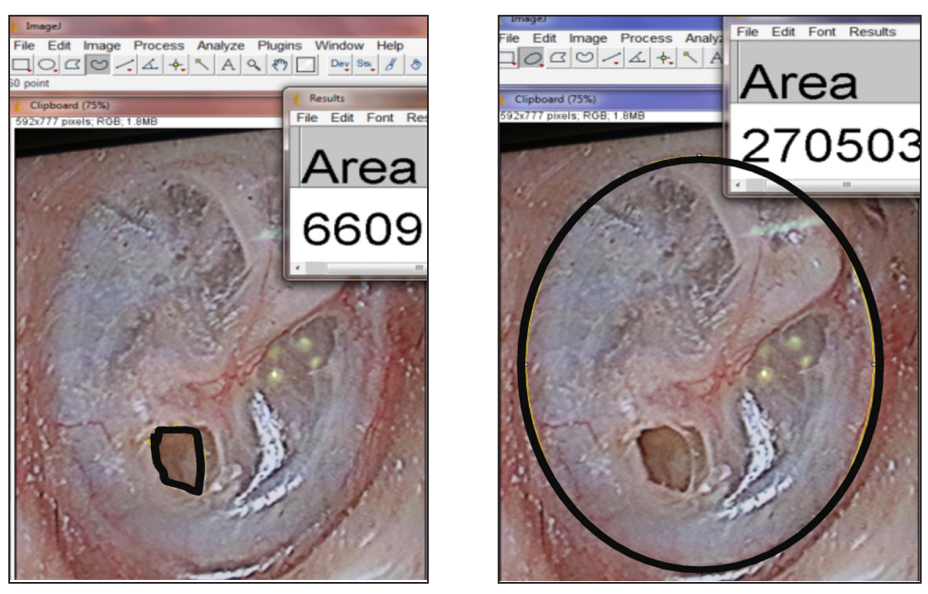

Figure 5. Sample measurement of area of perforation using Image J software, where surface area of perforation, $6609 /$ area of TM, $270503=<50 \%$.

\section{RESULTS}

Sixty four (64) participants, 18 (28\%) males and 46 (72\%) females with a male : female ratio of 1:2.5 completed the study. Their mean age was $27.85 \pm 12.05$ years while the range was $7-67$ years and median age of 25 years. Most ( $82.8 \%$ ) were between $15-44$ years of age, significantly higher than that of other age groups $(Z=9.27, p=.0001)$. (Table 1$)$

Most of the perforations $(51,79.7 \%)$ healed within three months. Among the 13 unhealed perforations, 6 developed ear discharge while the other 7 were dry. (Table 2 ) According to size, $95.7 \%$ of the perforations $\leq 50 \%$ healed within 3 months while $84.6 \%$ of the perforations $>50 \%$ remained unhealed at the end of 3 months. (Table 3) Chi-square test showed that there was a significant association between size of perforation and condition of the tympanic membrane after 3 months $(x 2=25.75 ; p=.00001)$. The risk of persistence of a perforated tympanic membrane was 34.57 times more among patients with a perforation size $>50 \%$ compared to patients with perforation size $\leq 50 \%$ [OR-34.57 $(6.28,190.14) ; p=.00001]$. (Figure 3) Most of the traumatic injuries were due to either explosive or non-explosive causes and none were iatrogenic or penetrating. In addition, majority $(61.5 \%)$ of the persistent perforations after 3 months were from explosive followed by non-explosive (38.5\%) injuries. (Figure 4) The most common explosive injuries were from bomb blasts, and the most common non-explosive injuries were from a slap over the ear arising out of domestic violence. Chi-square test showed a significant association between mode of injury and tympanic membrane condition after three months $(x 2=23.30 ; p=.00001)$. (Table 3)

There was no significant association between appearance of the perforation edges and healing of tympanic membrane perforation after 3 months ( $x 2=1.48 ; p=.47$ ). The healed and perforated cases were more or less equally distributed for all types of perforation edges. (Table 4)

There was no significant association between upper respiratory tract infections (URTI) and tympanic membrane healing after 3 months ( $x 2=1.83 ; p=.17)$. While $7.4 \%$ of cases with clinical evidence of URTI did not heal within 3 months, $29.7 \%$ of cases with no clinical evidence of URTI also did not heal within 3 months. (Table 5)

Combinations of factors were also analyzed and explosive etiology and perforation size $>50 \%$ were significantly associated with non-healing ( $x 2=37.60 ; p=.00001)$. (Table 6) Most of the persistent perforations after 3 months (53.8\%) were those with perforations of $>50 \%$ and explosive in etiology while $36.4 \%$ had perforations of $>50 \%$

Table 1. Age Distribution

\begin{tabular}{|c|c|c|}
\hline $\begin{array}{c}\text { Age Group } \\
\text { (in years) }\end{array}$ & Number (N) & Percentage (\%) \\
\hline$<15$ & 6 & $9.4 \%$ \\
\hline $15-44$ & 53 & $82.8 \%$ \\
\hline$>44$ & 5 & $7.8 \%$ \\
\hline Total & 64 & $100.0 \%$ \\
\hline
\end{tabular}

Table 2. Distribution of condition of tympanic membrane after 3 months Tympanic membrane condition after 3 months|Number Percentage (\%)

\begin{tabular}{|l|r|r|}
\hline Healed & 51 & $79.7 \%$ \\
\hline Persistent perforation with discharge & 6 & $9.4 \%$ \\
\hline Dry perforation & 7 & $10.9 \%$ \\
\hline Total & 64 & $100.0 \%$ \\
\hline
\end{tabular}


Table 3. Table showing healing of traumatic perforation of TM as a product of size and mode of injury

\begin{tabular}{|c|c|c|c|c|c|c|}
\hline \multirow[t]{2}{*}{ Factors } & \multicolumn{2}{|c|}{$\begin{array}{l}\text { Condition of TM } \\
\text { after } 3 \text { months }\end{array}$} & \multirow[t]{2}{*}{ Total } & \multirow{2}{*}{$\begin{array}{c}x^{2}- \\
\text { value }\end{array}$} & \multirow[t]{2}{*}{$p$-value } & \multirow{2}{*}{$\begin{array}{l}\text { Statistically } \\
\text { significant } \\
\text { (S) or not } \\
\text { (NS) }\end{array}$} \\
\hline & Healed & Perforated & & & & \\
\hline \begin{tabular}{|l|} 
Size of \\
Perforation
\end{tabular} & & & & 25.75 & .00001 & $S$ \\
\hline$\leq 50 \%$ & 44 & 2 & 46 & & & \\
\hline Row\% & 95.7 & 4.3 & 100.0 & & & \\
\hline Col \% & 86.3 & 15.4 & 71.9 & & & \\
\hline$>50 \%$ & 7 & 11 & 18 & & & \\
\hline Row\% & 38.9 & 61.1 & 100.0 & & & \\
\hline Col $\%$ & 13.7 & 84.6 & 28.1 & & & \\
\hline TOTAL & 51 & 13 & 64 & & & \\
\hline Row $\%$ & 79.7 & 20.3 & 100.0 & & & \\
\hline $\mathrm{Col} \%$ & 100.0 & 100.0 & 100.0 & & & \\
\hline $\begin{array}{l}\text { Mode of } \\
\text { injury }\end{array}$ & & & & 23.30 & .00001 & $S$ \\
\hline Explosive & 3 & 8 & 11 & & & \\
\hline Row\% & 27.3 & 72.7 & 100.0 & & & \\
\hline Col $\%$ & 5.9 & 61.5 & 17.2 & & & \\
\hline $\begin{array}{l}\text { Non- } \\
\text { explosive }\end{array}$ & 37 & 5 & 42 & & & \\
\hline Row\% & 88.1 & 11.9 & 100.0 & & & \\
\hline Col $\%$ & 72.5 & 38.5 & 65.6 & & & \\
\hline latrogenic & 6 & 0 & 6 & & & \\
\hline Row $\%$ & 100.0 & 0.0 & 100.0 & & & \\
\hline $\mathrm{Col} \%$ & 11.8 & 0.0 & 9.4 & & & \\
\hline Penetrating & 5 & 0 & 5 & & & \\
\hline Row $\%$ & 100.0 & 0.0 & 100.0 & & & \\
\hline $\mathrm{Col} \%$ & 9.8 & 0.0 & 7.8 & & & \\
\hline Total & 51 & 13 & 64 & & & \\
\hline Row\% & 79.7 & 20.3 & 100.0 & & & \\
\hline Col $\%$ & 100.0 & 100.0 & 100.0 & & & \\
\hline
\end{tabular}

and non-explosive etiology. Only $7.7 \%$ of persistent perforations after 3 months had perforations $\leq 50 \%$ AND explosive etiology and size of perforation $\leq 50 \%$ and non-explosive etiology combined. (Figure 5)

\section{DISCUSSION}

Trauma with its manifold manifestations is on an exponential rise in India given the diversity of political, cultural and social interests of its millions. This could be in form of assault, road traffic injury, domestic violence, industrial and sports injuries. This has significant economic
Table 4. Table showing healing of traumatic perforation of TM as a product of appearance of its edge

\begin{tabular}{|l|c|c|c|c|c|c|}
\multirow{2}{*}{ Factors } & \multicolumn{2}{|c|}{$\begin{array}{c}\text { Condition of TM } \\
\text { after }\end{array}$} & months & Total & $\boldsymbol{x}^{2}$ - \\
value & Healed & Perforated & & & $\begin{array}{c}\text { Statistically } \\
\text { significant } \\
\text { (S) or not } \\
\text { (NS) }\end{array}$ \\
\cline { 1 - 3 } $\begin{array}{l}\text { Edges of } \\
\text { Perforation }\end{array}$ & & & & 1.48 & .47 & NS \\
\hline Ragged & 21 & 3 & 24 & & & \\
Row\% & 87.5 & 12.5 & 100.0 & & & \\
Col \% & 41.2 & 23.1 & 37.5 & & & \\
\hline Everted & 14 & 5 & 19 & & & \\
Row\% & 73.7 & 26.3 & 100.0 & & & \\
Col \% & 27.5 & 38.5 & 29.7 & & & \\
\hline Inverted & 16 & 5 & 21 & & & \\
Row\% & 76.2 & 23.8 & 100.0 & & & \\
Col \% & 31.4 & 38.5 & 32.8 & & & \\
\hline Total & 51 & 13 & 64 & & & \\
Row\% & 79.7 & 20.3 & 100.0 & & & \\
Col \% & 100.0 & 100.0 & 100.0 & & & \\
\hline
\end{tabular}

Table 5. Table showing healing of traumatic perforation of TM due to effect of upper respiratory tract infection

\begin{tabular}{|l|c|c|c|c|c|c|}
\multirow{2}{*}{ Factors } & \multicolumn{2}{|c|}{$\begin{array}{c}\text { Condition of TM } \\
\text { after 3 months }\end{array}$} & Total & $\boldsymbol{x}^{2}$ - \\
value & Healed & Perforated & & & $\begin{array}{c}\text { Statistically } \\
\text { significant } \\
\text { (S) or not } \\
\text { (NS) }\end{array}$ \\
\cline { 1 - 5 } $\begin{array}{l}\text { Clinical } \\
\text { evidence } \\
\text { of URTI }\end{array}$ & & & & 1.83 & .17 & NS \\
\hline Yes & 25 & 2 & 27 & & & \\
Row\% & 92.6 & 7.4 & 100.0 & & & \\
Col \% & 49.0 & 15.4 & 42.2 & & & \\
\hline No & 26 & 11 & 37 & & & \\
Row\% & 70.3 & 29.7 & 100.0 & & & \\
Col \% & 51.0 & 84.6 & 57.8 & & & \\
\hline TOTAL & 51 & 13 & 64 & & & \\
Row\% & 79.7 & 20.3 & 100.0 & & & \\
Col \% & 100.0 & 100.0 & 100.0 & & & \\
\hline
\end{tabular}

and psychosocial impact at individual as well as national levels most of which is difficult to quantify. Trauma to the ear can range from simple to complex cases like blunt trauma, laceration, or avulsion of part or all of the pinna; uncomplicated tympanic membrane perforation; dislocation of the ossicles; and longitudinal and transverse fractures of 
ORIGINAL ARTICLES

Table 6. Composite table showing healing of TM as a product of size of perforation, mode of injuries and combinations of these factors with their correlation coefficient and statistical significance

\begin{tabular}{|c|c|c|c|c|c|c|}
\hline \multirow[t]{2}{*}{ Factors } & \multicolumn{2}{|c|}{$\begin{array}{l}\text { Condition of TM } \\
\text { after } 3 \text { months }\end{array}$} & \multirow{2}{*}{ Total } & \multirow{2}{*}{$\begin{array}{c}x^{2}- \\
\text { value }\end{array}$} & \multirow[t]{2}{*}{$p$-value } & \multirow{2}{*}{$\begin{array}{l}\text { Statistically } \\
\text { significant } \\
\text { (S) or not } \\
\text { (NS) }\end{array}$} \\
\hline & Healed & Perforated & & & & \\
\hline $\begin{array}{l}\text { Presence } \\
\text { of combi- } \\
\text { nation of } \\
\text { factors }\end{array}$ & & & & 37.60 & .00001 & $S$ \\
\hline $\begin{array}{l}\text { Size of } \\
\text { perforation } \\
>50 \% \\
+ \text { Explosive }\end{array}$ & 0 & 7 & 7 & & & \\
\hline Row\% & 0.0 & 100.0 & 100.0 & & & \\
\hline Col $\%$ & 0.0 & 53.8 & 10.9 & & & \\
\hline $\begin{array}{l}\text { Size of } \\
\text { perforation } \\
>50 \%+ \\
\text { Non } \\
\text { Explosive }\end{array}$ & 7 & 4 & 11 & & & \\
\hline Row\% & 63.6 & 36.4 & 100.0 & & & \\
\hline Col \% & 13.7 & 30.8 & 17.2 & & & \\
\hline $\begin{array}{l}\text { Size of } \\
\text { perforation } \\
\leq 50 \% \\
+ \text { Explosive }\end{array}$ & 3 & 1 & 4 & & & \\
\hline Row\% & 75.0 & 25.0 & 100.0 & & & \\
\hline Col \% & 5.9 & 7.7 & 6.3 & & & \\
\hline $\begin{array}{l}\text { Size of } \\
\text { perforation } \\
\leq 50 \%+ \\
\text { Non } \\
\text { Explosive }\end{array}$ & 41 & 1 & 42 & & & \\
\hline Row \% & 97.6 & 2.4 & 100.0 & & & \\
\hline Col \% & 80.4 & 7.7 & 65.6 & & & \\
\hline Total & 51 & 13 & 64 & & & \\
\hline Row\% & 79.7 & 20.3 & 100.0 & & & \\
\hline $\mathrm{Col} \%$ & 100.0 & 100.0 & 100.0 & & & \\
\hline
\end{tabular}

*S-Significant, **NS-Non-significant

the petrous temporal bone with associated loss of inner ear and facial nerve function. ${ }^{2,3}$

The current study focused on tympanic membrane perforation as a consequence of trauma. While the management of the otologic complications of trauma are well validated, tympanic membrane perforation has been considered to be mostly a self-healing condition.
Almost all standard textbooks and previous large scale studies consider a 'wait and watch' policy of management for traumatic tympanic membrane perforation. ${ }^{4}$ However, there is still a subset of patients, albeit small, who will not spontaneously heal and tend to suffer increased morbidity for three months. Our study attempts to identify this subset of patients who may benefit from early intervention based on certain risk factors, etiology and characteristics of the perforation. Our focus was to propose criteria based on a set of parameters for identification of these patients.

In our study the high ratio of females (72\%) may likely be due to increased domestic violence, corroborating the findings of other Indian studies. ${ }^{5}$ After 3 months of masterly inactivity, almost $80 \%$ (51) of the perforations healed spontaneously. Among the 13 unhealed cases, 6 developed discharge, a marker of increased morbidity. Other studies show similar rates of spontaneous healing.' In this study, non-healing perforations had a direct and statistically significant correlation with $>50 \%$ perforation, suggesting that there a 34.7 times greater chance of persistent perforation after 3 months when the perforation size is greater than $50 \%$ of the total tympanic membrane surface area. That larger perforations have less chances to heal spontaneously has also been shown by other studies. ${ }^{6}$

We used ImageJ software on photographs obtained during examination under microscope to calculate perforation size as a percentage of the size of whole tympanic membrane. (Figure 6) The reliability of ImageJ software has been validated in a previous quantitative analysis of tympanic membrane perforations compared to blinded data on perforation area obtained independently from assessments by two trained otologists.?

In this study the mode of injury was classified as explosive, iatrogenic, non-explosive (blunt trauma) and penetrating in accordance with a standard textbook. ${ }^{4}$ Of the 11 cases due to explosive injuries, 8 remained unhealed after three months of observation, and this was statistically significant. Previous studies show up to $62 \%$ non-healing after traumatic perforation from explosive injuries like bomb blasts. ${ }^{8}$ There was no statistically significant association between the condition of perforated margins or URTI and healing of the tympanic membrane in this study. There have been contradictory results regarding these findings in prior studies. Whereas inverted or everted edges compared with no curled edges did not significantly affect healing rate ${ }^{9}$ and edge approximation of inverted edges had little benefit in improving the healing outcome, ${ }^{10}$ the results of another study showed a definite correlation of non-healing with curled edges. ${ }^{11}$ The relationship with URTI was positively correlated in the study by Griffin et al. ${ }^{6}$ and accelerated healing has been shown 


\section{ORIGINAL ARTICLES}

following treatment with antibiotics and nasal decongestants, ${ }^{12}$ but URTI was found to have no correlation in the study of Lou et al. ${ }^{13}$

Our study categorized the non-healed cases into four groups based on combinations of statistically significant risk factors. All of the seven cases with $>50 \%$ perforation and explosive causes of perforation remained unhealed after three months. In the 11 cases where perforation was $>50 \%$ but the cause was not explosive, 4 cases remained unhealed. With perforation $<50 \%$ and explosive cause, 1 out of 4 case remained unhealed. Lastly, with perforation $<50 \%$ and nonexplosive cause, only 1 out of 42 remained unhealed. These results show a statistical significant association of non-healing when a $>50 \%$ perforation size and explosive cause are combined. This may provide a preliminary basis for stratification of patients into a high-risk group having a combination of these factors who might benefit from early intervention while groups having any one of these risk factors alone may benefit from close and stringent monitoring. To the best of our knowledge, there have been no prior studies in English proposing a similar risk-stratification for patients.

In conclusion, an explosive etiology and tympanic membrane perforation size $>50 \%$ may be significant risk factors predicting nonhealing of the perforation. Risk stratification of patients having one or both of these risk factors with early intervention for those with both and close monitoring for those with any one of these may lessen unnecessary morbidity. Bigger multicenter future studies are necessary to confirm these initial findings.

The authors would like to thank the Principal, R.G. Kar Medical College, Kolkata, India for allowing us to conduct the study.

\section{REFERENCES}

1. Kristensen S. Spontaneous healing of traumatic tympanic membrane perforations in man: A century of experience. J Laryngol Otol. 1992 Dec; 106(12): 1037-50. PMID: 1487657.

2. Ologe FE. Traumatic perforation of tympanic membrane in llorin, Nigeria. Nig J Surg. 2002; 8 (1): 9-12.

3. Toner JG, Kerr AG. Ear Trauma. In: Booth JB, Kerr AG, Groves J (editors). Scott-Brown's Otolaryngology. London: Butterworth Heinemann; 1997.p. 3/711-3/7/13.

4. Sismanis AA. Tympanoplasty: Tympanic Membrane Repair. In: Gulya AJ, Minor LB, Poe DS (editors). Glasscock-Shambaugh Surgery of the Ear 6th edition. New York: PMPH-USA; 2010. p 468.

5. Sarojamma, Raj S, Satish HS. A Clinical Study of Traumatic Perforation of Tympanic Membrane. IOSR-JDMS. 2014 Apr; 13(4): 24-28.

6. Griffin WL Jr. A retrospective study of traumatic tympanic membrane perforations in a clinical practice. Laryngoscope. 1979 Feb; 89 (2 part 1): 261-282. DOI: 10.1288/00005537-197902000 00009; PMID: 423665

7. Ibekwe TS, Adeosun AA, Nwaorgu OG. Quantitative analysis of tympanic membrane perforation: a simple and reliable method. J Laryngol Otol. 2009 Jan; 123(1): e2. DOI:10.1017/ S0022215108003800; PMID: 18940030

8. Miller IS, Mcgahey D, Law K. The otologic consequences of Omagh bomb disaster. Otolaryngo Head Neck Surg. 2002 Feb; 126(2): 127-8. DOI: 10.1067/mhn.2002.122186; PMID: 11870341

9. Lou ZC, Tang YM, Yang J. A prospective study evaluating spontaneous healing of aetiology, size and type-different groups of traumatic tympanic membrane perforation. Clin Otolaryngol. 2011 Oct; 36(5): 450-460.

10. Lou ZC, Wang YB. Healing outcomes of large (> 50\%) traumatic membrane perforations with inverted edges following no intervention, edge approximation and fibroblast growth factor application; a sequential allocation, three-armed trial. Clin Otolaryngol. 2013 Aug; 38(4): 289296. DOI: 10.1111/coa.12135; PMID: 23731690 PMCID: PMC4234003.

11. Shetty H, Gangadhar KS. Study of conservative treatment in traumatic perforation of tympanic membrane and its clinical outcome. IOSR-JDMS. 2015 Aug; 14(8):21-23.

12. Ng L, Monagle K, Monagle $P$, Newall F, Ignjatovic V. Topical use of antithrombotics: review of literature. Thromb Res. 2015 Apr; 135(4): 575-581. DOI: 10.1016/j.thromres.2015.01.006 PMID:25704903.

13. Lou ZC, Lou ZH, Zhang QP. Traumatic tympanic membrane perforations: a study of etiology and factors affecting outcome. Am J Otolaryngol. 2012 Sep-Oct; 33(5): 549-55. DOI: 10.1016/j. amjoto.2012.01.010; PMID: 22365389.
} 